IRA-International Journal of Education \&

Multidisciplinary Studies

ISSN 2455-2526; Vol.17, Issue o3 (Q3, 2021)

Pg. no. 122-129.

IRA Academico Research

\title{
Managing Professional Promotion Mechanism for Rural Teachers at the Pre-service Stage
}

\author{
Yang Chi ${ }^{\# 1^{\#}} \&$ Xu Hong ${ }^{2}$ \\ \# corresponding author. \\ Type of Work: Peer Reviewed. \\ DOI: $10.21013 /$ jems.v17.n3.p2 \\ DOI URL: https://dx.doi.org/10.21013/jems.v17.n3.p2
}

${ }^{1,2}$ College of Education and Sports, Yangtze University, Jingzhou, Hubei, 434000, P.R. China.

How to cite this paper:

Chi, Y., Hong, X. (2021). Managing Professional Promotion Mechanism for Rural Teachers at the Pre-service Stage. IRA-International Journal of Education \& Multidisciplinary Studies (ISSN 2455-2526), 17(3), 122-129. DOI: https://dx.doi.org/10.21013/jems.v17.n3.p2

(C) IRA Academico Research.

(oc) EY-NG This work is licensed under a Creative Commons Attribution-NonCommercial 4.0 International License subject to a proper citation to the publication source of the work.

Disclaimer: The scholarly papers as reviewed and published by IRA Academico Research are the views and opinions of their respective authors and are not the views or opinions of IRA Academico Research. IRA Academico Research disclaims any harm or loss caused due to the published content to any party.

IRA Academico Research is an institutional publisher member of Publishers International Linking Association Inc. (PILA-CrossRef), USA. IRA Academico Research is an institutional signatory to the Budapest Open Access Initiative. Hungary advocating the open access of scientific and scholarly knowledge. IRA Academico Research is a registered content provider under Open Access Initiative Protocol for Metadata Harvesting (OAI-PMH).

The journal is indexed \& included in WorldCat Discovery Service (USA), CrossRef Metadata Search (USA), WorldCat (USA), OCLC (USA), Open J-Gate (India), EZB (Germany) Scilit (Switzerland), Airiti (China), Bielefeld Academic Search Engine (BASE) of Bielefeld University, Germany, PKP Index of Simon Fraser University, Canada.

\footnotetext{
${ }^{1}$ Yang Chi is a student of Master of Higher Education, College of Education and Sports, Yangtze University, Jingzhou, Hubei, 434000, China.

${ }^{2} \mathrm{Xu}$ Hong is a Professor at College of Education and Sports Education of Yangtze University. Jingzhou, Hubei, 434000, China.
} 


\section{ABSTRACT}

Rural teachers' pre-service stage professional promotion mechanism refers to a series of rule-based systems of incentives, constraints and guarantees implemented to promote rural teachers' professional growth before they enter into the profession. At present, although the pre-service stage professional promotion mechanism of rural teachers in China has various forms and fruitful contents, the effectiveness of its implementation is very limited. This paper argues that the enrollment mechanism of orientation and priority for rural children, the training mechanism of public funding and contract flexibility, and competition for entry into the countryside, with the compilation of the post, are the current effective mechanisms to promote the professional growth of rural teachers at the pre-service stage.

Keywords: rural teachers, pre-service phase of rural teachers, promotion mechanism

Rural teachers are not only the first resource for rural education, but also an important foundation for the construction of material and spiritual civilization in rural society, and an indispensable force for the balanced development of urban and rural basic education and educational equity and even social equity ${ }^{[1]}$. The high-quality development of rural education depends on the professional growth of rural teachers. From the perspective of teacher education integration, the pre-service professional growth of rural teachers is an important part of the entire teacher professional development stage. In recent years, in order to promote the professional growth of rural teachers at the pre-service stage, China has introduced a series of policies and mechanisms such as "publicly funded teacher training", "directed rural teacher training", "open recruitment and directed employment "At the same time, many scholars have done a lot of exploration in this area. For example, based on the perspective of the three dimensions of teacher excellence, Shiwei proposes that China should strengthen institutional construction, enhance teacher training, and create a relaxed environment to promote the cultivation of exceptional rural teachers through exploring the mechanism of the pre-service training stage of rural teachers ${ }^{[2]}$; Based on the dilemma of "localized" professional development of rural teachers, Zhang Yewen and Xiao Qiyong proposed a mechanism for "localized" professional development mechanism for pre-service training of rural teachers ${ }^{[3]}$; After reflecting on the construction of a professional development support system for rural teachers, Yukun Zhuang and Yuanhui Chu argue that the current pre-service training mechanism needs to be worked on in terms of cooperation and symbiosis among the personnel of various institutions, using the study of the construction of a professional development support system for rural teachers as a background ${ }^{[4]}$. Although these policies have achieved some results in the professional growth of rural teachers in the pre-service stage, and the related research results have also been useful in promoting the mechanism of promoting rural teachers in the pre-service stage. However, in practice, there are still problems with the pre-service promotion mechanism for rural teachers, such as "the number of publicly funded teacher trainees breaking their contracts," "the attractiveness to young rural teachers is not strong," and "teacher trainees cannot teach well and cannot go down." These problems also reveal the weakness and inadequate implementation of the pre-service professional promotion mechanism for rural teachers. In order to more effectively enhance and improve the existing pre-service stage professional promotion mechanism for rural teachers, this paper argues that we can start from three aspects: the enrollment mechanism of orientation and single enrollment and priority for rural children, the training mechanism of public funding and contract flexibility, and the employment mechanism of competition for entry into the countryside and employment with an editor.

\section{The Enrollment Mechanism of Targeting a Single, Rural Child Priority}

The so-called orientation single, rural children priority enrollment mechanism, refers to the local education administrative departments, under the guidance of relevant national policies, in the admission of students to the college entrance examination, giving priority to students of rural origin, and concentrated training, a clear direction of their employment after graduation with an institutional rule.

In order to promote the professional growth of rural teachers at the pre-service stage, China has introduced a series of mechanisms, such as teacher training reform, teacher education innovation, new-age team building, publicly funded teacher training and local teacher training, etc. At the same time, some local universities with directed teacher training students have also reformed their teacher training curriculum and strengthened practical teaching, which has to some extent increased the number of rural teachers and improved the composition of rural teachers. To some extent, this has increased the number of rural teachers and improved the composition of rural teachers, thus to some extent alleviating the situation that rural teachers are "unable to go down". Unfortunately, there are still some problems with these policy mechanisms in practice, for example, students do 
not have good access to information at the time of enrollment, and the government's policy on targeted teacher training is not well-publicized, so students mostly follow their parents' wishes when applying for the program, or apply for it because of job security and good development opportunities. In the process of training teacher-training students, the cost of training is high, but it takes a long time to achieve results. Due to the lack of understanding of the policy when the teacher-training students apply, some of them do not want to be teachers during the study process, and they are teachers in rural areas where the conditions are relatively difficult. "Finally, orientation teacher training stipulates that teacher trainees must teach in rural areas after graduation according to the contract, although most of the sources of orientation teacher trainees are candidates from rural areas, after a few years of study, they are exposed to a completely different urban lifestyle from rural areas, and some teacher trainees who go to teach in rural areas are not native rural sources, they may not adapt to the local way of life and thus are less able to integrate into the countryside. For this reason, in order to promote the recruitment of high-quality rural teachers and stabilize the rural teaching force, it is necessary to implement the enrollment mechanism of "orientation and priority for rural children" for three main reasons.

For one thing, the implementation of "orientation" training is conducive to giving rural oriented teacher trainees a clear understanding of their future career as rural teachers, so that they can have a clear career plan during their school years, learn to make trade-offs, and improve their sense of commitment. And in the process of high school students learning about the rural teaching profession, if they feel they are not suitable for this career, they can choose not to apply for directed teacher training students, to avoid applying for directed teacher training students with utilitarian purposes because of rural policy support and rural teaching with preparation. Based on this, society and schools should publicize in advance the content, purpose and significance of the rural orientation teacher training policy, so that students applying for the policy have a fuller understanding of the policy. Second, the use of a "single" enrollment plan is conducive to the targeted training of targeted teacher training students in colleges and universities. In the process of training teachers in rural areas, teacher-training students have to learn not only the basic theoretical courses of teacher education, but also additional courses on the local curriculum, rural emotional education and rural customs and people, and because the conditions of rural internship are difficult, students from colleges and universities are not willing to go to rural internship, which makes it difficult for colleges and universities to coordinate students from rural and urban internships. Therefore, it is difficult for colleges and universities to train oriented teacher trainees, and they are less willing to recruit oriented rural teacher trainees. If a "single" system is adopted in the enrollment process, it will be helpful for colleges and universities to unify students to go to rural areas for an internship, so as to avoid the disadvantage of scattered internship sites for teacher-training students, which is difficult for schools to manage; thirdly, the implementation of the enrollment system that gives priority to "rural children" will be helpful for improving the student source in rural areas. Third, the implementation of the "country boy" priority enrollment system is conducive to improving the quality of rural students. As "country children" born and raised in the countryside, they often have special feelings for the countryside, although they may not have a systematic understanding of the countryside's folk customs, they are growing up in the process, are implicitly absorbed by this culture, so "country children "In the process of orientation training, the "village children" will also have the foundation of village related courses, and it will be easier to adapt to the village life during the internship process, and will not suffer from physical conditions caused by the discomfort of the soil and water. It is also easier to teach and communicate with students, and they can get along with them better. If the oriented teacher trainees are assigned to an internship in their alma mater, they will have more affection for their alma mater, and they will be able to devote themselves to the internship better under the systematic guidance of their alma mater teachers, thus avoiding the phenomenon of "perfunctory" internship of teacher trainees nowadays. It is of great significance to improve the effectiveness of the training process of universities, increase the chance of returning to school and improve the cost of orientation training. Especially worth mentioning is the "priority" system, once more teacher-training students are willing to teach in the countryside, and in the case of the lack of "village children" students, if there are other teacher-training students from the city, for example, due to the influence of their grandparents, have a special affection for the countryside If there are other teacher trainees from the city, such as those who have been influenced by their grandparents and have special feelings for the countryside and are willing to teach in the countryside, they can also be considered. Even though it is a "country boy first" system, it does not exclude children who have a love for the countryside and can be tested for their countryside identity and psychological qualities before teaching. If the "country boy" lacks a rural identity, he can be considered for transfer to a general class. Likewise, if a child from the city passes the psychological test and is willing to be ordinary and lonely, and does not pursue a luxurious city life, he or she can also take a rural teaching position. 
From the current situation of China and the countryside, in order to more effectively implement the "directional single, the country child priority" enrollment mechanism, specific initiatives should start from the following aspects.

First of all, in the formulation of policies, the "orientation" form of training should be highlighted. The state should not only increase funding for rural teacher education research but also strengthen research on the "targeted and separate" enrollment mechanism. At the same time, the state should also delegate certain powers to local county-level education administrative departments. The key to targeted teacher training for local students lies in local county-level education administrative departments, and the state can consider returning teacher recruitment management and deployment powers to county-level education administrative departments, allowing them to implement targeted recruitment, targeted training, and targeted assignment of rural teachers according to local realities and in conjunction with the establishment shortage, local teacher training programs ${ }^{[5]}$, create a favourable environment for the training of directed teacher trainees. Second, the state also needs to highlight the "separate" form of teacher training student enrollment. In the actual application process of directed rural teacher training students, most of the high school students do not know much about the rural teacher support program, team building, welfare and its implementation from the central to the local level, and their information is mainly obtained through friends and relatives, school propaganda and internet resources. Most of the high school students are passive applicants, they do not understand the responsibility and nature of their future career, and they do not have a clear career plan, which means that the society's policy for directed teacher training students is not in place. Therefore, the society has to understand the nature and meaning of directed teacher training students, the current situation of rural education and rural customs, life and production methods, and the priority policy support for "rural children" through the internet and mainstream media, so that students can have a clearer understanding. After enrolling the candidates and arranging for their admission, the school should target the training of rural teachers in a specific and specific way, adding courses such as the history of rural education, emotional education of rural teachers, and introduction to the student population and overall situation of rural schools to the training curriculum."The quality of rural teachers is by no means only the amount of knowledge and the level of education, but also the closeness to the rural community and the love of broadcasting, that is, the strong local emotion" ${ }^{\text {"[6] }}$.In the process of recruiting and training rural teachers, local sensibilities should be an important assessment criterion for schools and governments. In order to promote the reform of pre-service training of rural teachers, Australia has implemented such measures as "bundled" student incentive programs, curriculum design around "countryside", and practical experience in the "field". These measures are worth learning from in China ${ }^{[7]}$. Finally, in terms of policy implementation, the rule of "rural children (rural candidates) first" was adopted to moderately favour rural students and bring into play the "locals" effect of the teacher labour market. The "local" effect in the teacher labour market. Under equal conditions, priority will be given to teacher-training students from rural areas, followed by urban teacher-training students. However, if some teacher-training students from urban areas and certain schools in rural areas have commissions, they may also be considered for recruitment of teacher-training students from rural areas before those from urban areas. The local government should implement the policy system, establish a green channel for "village children" to teach in villages on a priority basis, and plan and selectively train teachers from the "village children" program to meet the actual requirements of local education development. Free teacher-training students in the compulsory education stage, directed to work in rural schools after graduation, in order to ensure the quality and stability of the rural teaching force sources. For those non-rural teacher trainees who are rooted in the culture of the countryside and love rural education, if they pass the relevant tests, they can also be allowed to enjoy the establishment and work as teachers in the countryside, so that the best teacher trainees who love education will be willing to stay in the countryside to teach ${ }^{[8]}$.At the same time, schools should also provide guidance to students in applying for the teacher training program, so that students have a clear understanding of the program through brochures and documentaries on rural teacher education, and teachers should guide students to apply for the program out of love and recognition of rural teachers, rather than because of job security and preparation. The higher education institutions should strengthen the connection with the local government for localized training of "village children" to ensure that "village children" can successfully go to the countryside to teach as a priority.

\section{Publicly Funded, Contractually Flexible Training Mechanism}

The so-called "publicly funded and flexible contract" training mechanism refers to the fact that in the training process of teacher-training students, teacher-training institutions (including comprehensive universities with teacher education departments) conditionally accept a certain amount of publicly funded education and subsidies for teacher-training students, and require them to sign a contract with the school and the county-level local 
administration where they will teach after graduation, so as to ensure that teacher-training students have the initiative in the contract process. This is a mechanism to ensure that teacher trainees have the right to take the initiative in the contractual process.

At present, China has introduced a targeted training system for publicly funded teacher-training students, which has achieved some results in the actual process, such as reducing the family burden of teacher-training students to a certain extent, improving the quality of rural teachers, and thus to some extent alleviating the situation that rural teachers "can't get off". However, there are some shortcomings in the implementation of the publicly funded teacher training system. First, the implementation of the publicly funded teacher training policy is not extensive, and the scope of its directed training is limited to teacher trainees from the six teacher training colleges directly under the Ministry of Education, which is far from meeting the demand for teachers in the vast rural areas of China. "Secondly, the publicly funded teacher training policy lacks a corresponding "exit" mechanism. The targeted training policy stipulates that teacher trainees may not transfer to majors other than teacher training during their training period, and if they want to change majors, they can only adjust between different majors in the teacher training category. Find that they are not interested in the teaching profession during their training; they can only continue their studies, leading to the common phenomenon of publicly funded teacher trainees breaking their contracts after graduation. Finally, teacher trainees' professional skills in rural teaching are not strong, and their recognition of the rural teaching profession is not high. According to Li Xin's survey on the employment status of Hunan's publicly funded teacher-training students, it was found that only $2.33 \%$ of the publicly funded teacher-training students were satisfied with the jobs assigned to them after graduation, and only $4.86 \%$ thought they would stay in the teaching profession, and $2.15 \%$ were likely to give up the teaching profession, indicating that the publicly funded teacher-training students did not have a sufficient sense of the nature of the rural teaching profession, responsibility and recognition during their training ${ }^{[9]}$.

In order to further improve these situations, it is necessary to reform the existing mechanism and implement a "publicly funded, contractually flexible" admissions mechanism for three main reasons.

Firstly, the implementation of the "publicly funded" training mechanism is conducive to expanding the sources of rural teachers. In addition to the six teacher-training colleges directly under the Ministry of Education as stipulated in the national policy on publicly-funded teacher-training, the "publicly-funded" mechanism also includes teacher-training majors of comprehensive universities and all other teacher-training colleges. Secondly, the "flexible contract" system is conducive to the sound "exit" mechanism of directed teacher-training students. In the process of training teacher-training students, some teacher-training students may have a stronger interest in other majors in the process of study, but they can only continue to study due to the restrictions of the contract, and even if they end up teaching in the countryside, they are not really interested in the countryside. The "flexible contract" system gives the teacher-training students one year to think about their career and stipulates that colleges and universities offer courses on local culture, the current situation of rural education, and emotional education for rural teachers in the first year of their enrollment. If, after one year of study, the student still insists on his or her original intention, he or she can continue to sign a contract and be trained in accordance with the contract; likewise, if he or she wants to transfer to another major, he or she can flexibly "withdraw" and does not need to pay for breach of contract. Third, it is conducive to saving the training cost of higher education institutions and improving their training quality. The "publicly funded, flexible contract" mechanism allows all teacher trainees who are willing to work as rural teachers to participate in the training of nationally oriented rural teacher trainees, but after one year of study in rural-related courses, teacher trainees are free to "withdraw" from the program and allow more teachers who are interested or interested in rural teaching to "withdraw" from the program. More students who are interested in or strongly identify with rural teachers can be included in the targeted teacher training by passing a test on basic knowledge of rural education and the psychological qualities of rural teachers, thus effectively preventing some teacher trainees who are not interested in rural education from defaulting or not teaching in rural areas after graduation, resulting in wasted training capital. Moreover, the teacher trainees who stay after one year of study will have a better learning effect at the later stage of study because of their foundation and their love and recognition of rural education.

In order to implement the "publicly funded, contractually flexible" training mechanism more effectively, the following specific measures can be adopted.

First of all, in terms of funding targets and methods, the state should strengthen the study of the "publicly funded, contractually flexible" training mechanism, expand the scope of targeted teacher training, extend the 
scope of the publicly funded teacher training policy to include teacher trainees from comprehensive universities and secondary schools, and increase the enthusiasm of teacher trainees to enrol in publicly funded programs, so that teacher trainees can feel the state's The policy should be implemented by local governments. The local government should implement the policy system and strengthen the propaganda of the policy, making it clear that all students who love the countryside and have a sense of identification with rural teachers can apply for the targeted teacher training program, and that the state is willing to provide publicly funded subsidies for tuition, living expenses and accommodation after they are admitted. Second, in the process of training, schools can adopt a contractually flexible approach and stipulate that in the first year of training for oriented teacher trainees, higher education institutions offer courses on native culture and rural emotional education to provide a comprehensive introduction to the countryside and rural teachers, so that teacher trainees can seriously understand the responsibilities and nature of rural teachers and give oriented teacher trainees room for consideration, and if teacher trainees, after one year of study want to transfer to other majors, they can also withdraw flexibly. At the same time, other majors who want to enter the training of oriented teacher-training students can be given appropriate opportunities, and the state will provide them with a one-time public subsidy. The state should make it clear to students that all students who love the countryside and identify with rural teachers can apply for directed teacher training, and that the state is willing to provide publicly funded subsidies for tuition, living expenses, housing, and research funding. Students should also be aware that even if they are unable to identify with the rural teaching profession during the training process (limited to the first year of training) or are unwilling to teach in the countryside after graduation, they can still withdraw from the teacher training program without having to pay a default fee. Furthermore, at the school level, schools should establish a curriculum that meets the goals of rural teacher training and develop their own "exit" mechanism so that students have the right to take the initiative in the contract. In the first two years of their training, schools can incorporate a curriculum on rural culture and local emotion education, and at the same time examine students' thoughts, grades, and conduct in various aspects, so that teachers and classmates can monitor each other and screen out students who lack teacher ethics, have unhealthy thoughts, and poor living habits so that they can be prepared to accept rural teaching positions. Incorporate practical courses in the second two years of teacher training, increase the proportion of practical teaching in the curriculum system, appropriately extend the student internship period, and encourage students to go to rural schools for internship let teacher trainees determine whether they can become a qualified rural teacher through the internship, plus the supervision and guidance of internship supervisors. Finally, at the time of graduation, the overall performance of students will be evaluated for graduation.

\section{Competition for Entry into the Countryside, with the Compilation of the Post}

The employment mechanism of "competing to enter the township and taking up the post" refers to the competitive arrangement for publicly funded teacher trainees to teach in the township according to their performance and comprehensive quality assessment, and a mechanism to ensure that they have a post when they serve.

The current employment mechanism of "open recruitment and targeted employment" in China has achieved a series of results in practice, such as ensuring the employment of targeted teacher trainees to a certain extent and attracting more young people to work as rural teachers, thus to some extent alleviating the situation that rural teachers "cannot teach and cannot be retained. To some extent, this has alleviated the situation that rural teachers "cannot be taught well and cannot be retained". However, there are some shortcomings in the "directed employment" mechanism, for example, due to the fact that directed employment improves the employment security of teacher-training students and the homogeneity of the training methods of higher education institutions, some publicly funded directed teacher-training students tend to lack competitiveness in the study and lack of goals in life, which leads to the situation of "muddling through" in school and at work. "In order to further improve these defects, it is necessary to reform the existing mechanism and implement the enrollment mechanism of "competing to enter the countryside and taking up the post", for three main reasons.

First, the system of "competition to enter the countryside" is conducive to correcting the study attitude of oriented teacher trainees and improving their motivation to study. The "competition to enter the countryside" system gives priority to those teacher trainees with local sentiment and excellent academic performance in the interview of teacher trainees in rural schools. The final scores are used to arrange their rural teaching positions. Secondly, the incentive mechanism of "taking up the job with the editor" is conducive to the renewal of the rural teaching force. First, the age and structure of rural teachers are contradictory, and the phenomenon of ageing is serious, and some teachers occupy the establishment for a long time but do not undertake the corresponding 
IRA-International Journal of Education \& Multidisciplinary Studies

teaching tasks, resulting in excellent teachers "not coming in" and out-of-service teachers "not leaving". Secondly, there is a tendency for rural teachers to deviate from the subject allocation, and school development tends to supplement the main subject teachers of language and mathematics, while there is a serious shortage of full-time teachers of minor subjects; finally, there is an unreasonable configuration of rural class teacher ratio, which puts rural teachers in an overstaffed state ${ }^{[10]}$. At present, the employment mechanism in China is characterized by a shortage of both staff and personnel, and the problem of easy loss of good teachers. In this way, more young teachers can be retained and the rural teaching force can be renewed. Finally, the employment mechanism of "competing to enter the countryside and taking up a job with a compilation" is conducive to the stability of the rural teaching force. Local education administrations limit the number of rural teachers to the number of rural teachers in the countryside. Although the targeted teacher-training students signed contracts with the state before they were employed, in practice, some publicly funded teacher-training students did not actually teach in rural areas after graduation, and even if they did teach in rural areas, they did so for the purpose of taking up teaching positions, but they chose to leave the countryside after obtaining their positions, only using the countryside as a springboard for their own work experience and career advancement. The establishment of a special rural establishment, to a certain extent, avoids the flow of rural teachers, because if rural teachers want to serve in the city, they must again take the urban teaching establishment, thus contributing to the stability of the rural teaching force.

In order to more effectively implement the employment mechanism of "competition for entry into the countryside, with the editorial", the following specific initiatives can be adopted.

First, with regard to the employment threshold of rural teachers, for rural areas with relatively tough conditions, the motivation of directed teacher trainees to teach in rural areas can be encouraged by raising the salaries of teachers there, giving corresponding subsidies and tilting policies in terms of assessing titles. At the same time, the state should reform the teacher qualification certificate, so that non-teaching students can also compete for rural teaching positions and also come with the same preparation, thus giving publicly funded teacher trainees potential employment pressure and increasing their motivation to study. Second, some foreign studies have shown that low trust in education regulations and policies and reforms and low opportunities for job advancement also affect rural teachers' intention to leave ${ }^{[11]}$. The state also needs to increase the incentive for oriented teacher training students through the formulation of education regulations and policies, such as changing the "partial return of studies after 3 years of graduation" to a pre-service "rural teacher scholarship" incentive, which not only can attract high-quality students and enhance the motivation of oriented students, but also can greatly enhance the sense of honour of the oriented students. This will not only attract high-quality students, enhance the enthusiasm of the targeted students, but also greatly enhance the sense of the glory of the targeted students. For those students who repeatedly violate discipline or fail in their courses, a system of "remission" or revocation of rural teacher status will be implemented based on their overall performance ${ }^{[12]}$. At the same time, schools should also strengthen the academic guidance for directed teacher trainees. Not only should schools strengthen the warning and educational guidance for students who are slack in their studies by establishing growth files of rural teacher-training students, promote self-growth and self-reflection of teacher-training students, encourage them to pursue excellence, and cultivate their sense of responsibility and dedication, but also increase the internship in directed rural schools and actively carry out exchange activities for directed teacher-training students into rural schools, so that teacher-training students can flexibly apply their learned We also need to strengthen the internship in rural schools and actively carry out the exchange activities for the teacher-training students to go to rural schools so that the teacher-training students can flexibly use their theoretical knowledge in practice and feel the current situation of rural education and understand the characteristics of rural education ${ }^{[13]}$.In this process, teacher trainees also need to raise their academic requirements and motivation so that they can learn more professional theoretical knowledge in the training process so that they can apply it to specific rural education practices and clarify the responsibilities and duties that rural teachers have to undertake through their studies. At the same time, teacher-training students should also establish a correct view of career selection and look at the rural teaching profession and other professions with an equal eye. Every profession in the world is great and indispensable, and there is no distinction between noble and lowly labour. Only when teacher-training students look at every profession in the world with an equal eye can they respect and take each profession seriously. Likewise, as long as teacher trainees look at the rural teaching profession with equal and respectful eyes and try to shine in this profession, their lives will surely be great and shine as a result. Finally, the state should establish a system of special preparation for rural teachers, so that if a rural teacher has any career change during his or her tenure, he or she will lose the special preparation for rural teachers once he or she leaves the countryside. The state should set limits on the number of 
IRA-International Journal of Education \& Multidisciplinary Studies

rural teachers who can be appointed to the "teaching posts" system, and stipulate that this is a special preparation for rural teachers only and that if a rural teacher changes his or her position during his or her tenure and wants to be promoted to teach in the city, the special preparation will be cancelled. Therefore, schools should also strengthen the publicity of the "competitive entry into the countryside, with the compilation of employment" mechanism. The schools should make it clear to the teacher trainees that the preparation for rural teaching positions is a special preparation for rural teachers. Specifically, if a teacher-training student leaves the countryside to teach in the city, his or her rural preparation will not be taken away from him or her.

\section{References}

[1]. Xu Hong, Dong Zefang. Characteristics and inspiration of rural teacher research in developed countries [J]. Educational Science, 2020,36(1):43-50.

[2]. Shi Wei. Teaching Excellence: A Pathway Choice for Excellence in Rural Teacher Training. Jiangsu Higher Education, 2020(4):35-40.

[3]. Zhang Yewen, Xiao Qiyong. Study on the construction of "localized" professional development mechanism for rural teachers [J]. Journal of Education (First Half), 2020,(3):85-90.

[4]. Zhuang YK, Chu Yuanhui. Construction of support system for rural teachers' professional development [J]. Foreign Education Research.2018.45(9):43-56.

[5]. Wu, Qing Yi. Theoretical starting point, practical basis and strategic analysis of localized training of rural teachers [J]. Teaching and management: theory edition,2017(12):51-53.

[6]. Wang Jiayi. Rural teachers in a multidimensional perspective [M]. Beijing: Beijing Normal University Press, 2011: 69-71.

[7]. Xie Yizhuan. Pre-service teacher training reform in rural Australia: motivations, strategies and insights. Foreign Education Research,2018,45(9):43-56.

[8]. Huang Muqian, Zhang Weixiang,Chen Doudou. A study on the mobility willingness of rural teachers in poor areas of Guangdong Province [J]. Journal of Lanzhou College of Education,2019(3):168-171.

[9]. Li X. Seeking a balance between quantity and quality of employment of publicly funded teacher-training students--a survey on the employment status of publicly funded teacher-training students in Hunan [J]. Shanghai Education Research, 2013,(11):36-39.

[10]. Yang, Liu, Zhang, Xu. A realistic reflection on the dilemma of rural teacher preparation [J]. Educational Development Research,2016,33(15):24-30.

[11]. Liu, S., Onwuegbuzie, J.. Chinese teachers' work stress and their turnover intention [J]. International Journal of Educational Research,2012(2): 160-170.

[12]. Xin Xianjun, Xu Xinping. The effectiveness, problems and countermeasures of rural teachers' orientation training[J]. Education Review, 2020,(2):115-119.

[13]. Duan Zhigui, Ning Yaoying, Chen Xingyue. Targeted rural teacher trainees return to teach in rural areas: myths and analysis [J]. Primary and secondary school teacher training,2020,(7):20-23. 